\title{
Especie nueva de alacrán del género Centruroides (Scorpiones: Buthidae) de la costa del estado de Jalisco, México
}

\section{A new scorpion species of the genus Centruroides (Scorpiones: Buthidae) from the coast of the state of Jalisco, Mexico}

\author{
Javier Ponce-Saavedra ${ }^{1}$ y Óscar F. Francke ${ }^{2}$ \\ ${ }^{1}$ Laboratorio de Entomología Biól. Sócrates Cisneros Paz, Facultad de Biología, Universidad Michoacana de San Nicolás de Hidalgo. Edificio B-4, $2^{0}$ \\ piso, Ciudad Universitaria 58060 Morelia, Michoacán, México. \\ ${ }^{2}$ Departamento de Zoología, Instituto de Biología, Universidad Nacional Autónoma de México. Apartado postal 70-153, 04510 México, D.F., México. \\ \javierpon@gmail.com
}

\begin{abstract}
Resumen. Se describe Centruroides chamela sp. nov. de Chamela en el estado de Jalisco, México. Se compara con C. elegans (Thorell), especie con la que es simpátrida. También se compara con las especies morfológica y geográficamente más cercanas: C. mascota Ponce-Saavedra y Francke, C. hirsutipalpus Ponce-Saavedra y Francke y C. tecomanus Hoffmann. Además, con C. meisei Hoffmann, que habita en las costas de Guerrero, porque este taxón se había considerado como subespecie de C. elegans. En la comparación se incluyen C. infamatus (C.L. Koch) y C. ornatus (Pocock), por ser especies "rayadas" registradas para el estado de Jalisco.

Palabras clave: Buthidae, Centruroides, nueva especie, sistemática, Jalisco, México.

Abstract. Centruroides chamela sp. nov. from Chamela, Jalisco, Mexico is described. The new species is compared primarily with $C$. elegans Thorell, because both species are sympatric. It is also compared with C. mascota Ponce-Saavedra et Francke, C. hirsutipalpus Ponce-Saavedra et Francke and C. tecomanus Hoffmann which are morphologically and geographically nearest to the new species. Centruroides meisei Hoffmann, which inhabits the coast of Guerrero is compared because this species was previously classified as a subspecies of C. elegans. Finally, $C$. infamatus (C.L. Koch) and C. ornatus (Pocock) are included in the comparisons because they are also present in the state of Jalisco, and belong to the "striped" section of the genus.
\end{abstract}

Key words: Buthidae, Centruroides, new species, systematics, Jalisco, Mexico.

\section{Introducción}

En la actualidad, Centruroides Marx, 1890 contiene 66 especies y 10 subespecies, todas del Nuevo Mundo, de las cuales se han registrado 37 especies para México (De Armas et al., 2003; Ponce-Saavedra y Moreno, 2005; Rein, 2010; Francke, datos no publicados). En estos datos ya se incluyen 2 especies que han sido elevadas a la categoría específica en los últimos años (De Armas y Martín-Frías, 2008; Ponce-Saavedra et al., 2009) y 1 descrita recientemente (Ponce-Saavedra y Francke, 2011). Pocock (1902) es el primer autor que separa los alacranes "rayados" del género Centruroides de los que presentan coloración uniforme. Los separa en 3 especies, una de las cuales es $C$. elegans (Thorell, 1876), que con sus 4 líneas bien distintas sobre el carapacho se diferencia con facilidad de $C$. vittatus (Say, 1821) y C. ornatus (Pocock, 1902), espe-

Recibido: 10 febrero 2011; aceptado: 06 mayo 2011 cies con el carapacho sin líneas definidas y obscurecido en su mayor parte por pigmento negro. Esta separación fue posteriormente retomada por Hoffmann (1932), para formar 2 grupos reconocibles de alacranes "rayados": A) con 4 líneas definidas y B) sin líneas definidas y la mayor parte del carapacho con pigmento negro. Posteriormente, González-Santillán (2001) propone una agrupación más fina para todas las especies del género, que en la mayoría de los casos toma algunas especies como referente para nominarlos y que permite reconocer 4 grupos de especies: (a) grupo "rayados", que incluye las especies con 2 bandas longitudinales obscuras flanqueando una banda amarilla mesal que les da la apariencia "rayada" y con 4 líneas bien definidas en el carapacho o con pigmento obscuro sin líneas definidas; (b) grupo "bertholdii", que son especies con 8 hileras o series de granulaciones en el borde interno de los dedos de los pedipalpos y sin "rayas" dorsalmente; (c) grupo "gracilis", que incluye especies con 9 hileras de granulaciones en el borde interno de los dedos de los pedipalpos y sin "rayas" dorsalmente, y (d) grupo "tho- 
relli”, con especies de tamaño pequeño con pigmentación en forma de manchas sin llegar a constituir bandas y con hábitos arborícolas. Las especies mexicanas del grupo de los "rayados" son de taxonomía difícil debido a su similitud morfológica, lo que hace muy complicado diferenciarlas, situación ya mencionada por Kraepelin (1899, en Hoffmann, 1932) y el propio Hoffmann (1932), y evidenciada por la aseveración de que las especies "rayadas" pueden distinguirse mejor con criterios geográficos más que morfológicos.

Para el estado de Jalisco se han registrado 14 especies de alacranes (Cuadro 1), de las cuales se tiene la certeza que 6 pertenecen a Centruroides: C. bertholdii (Thorell, 1876) del grupo de los "no rayados" sensu Hoffmann (1932) y C. elegans, C. infamatus, C. ornatus, C. tecomanus Hoffman, 1932 y C. mascota Ponce-Saavedra y Francke, 2010, dentro del grupo de los "rayados" (Hoffmann, 1931, 1932; Beutelspacher, 2000; Fet et al., 2000; Lourenço y Sissom, 2000; González-Santillán, 2001; González Santillán, 2004; Ponce-Saavedra y Moreno, 2005; Ponce-Saavedra y Francke, 2009, 2011; Quijano-Ravell et al., 2010). En el área de Chamela, Jalisco, dentro de la Estación Biológica de la UNAM, Williams (1986) registró 2 familias de alacranes: Buthidae representada por C. elegans y Vaejovidae con 3 especies. Beutelspacher (1999) informó sobre la presencia de algunos alacranes en bromelias; posteriormente, González-Santillán (2004) los reconoció como una especie nueva de Centruroides, de la cual menciona un patrón de coloración idéntico al de C. elegans, con diferencias importantes en el número de dientes pectíneos y la proporción largo/ancho del segmento caudal V, por lo que la identifica como un taxón afín a C. elegans. González-Santillán (2004) mencionó también haber encontrado algunos ejemplares en plantas epífitas del género Tillandsia y otros en el suelo.

El objetivo principal de esta contribución es describir una nueva especie del género Centruroides para México.

\section{Materiales y métodos}

Se revisaron 17 ejemplares adultos $(9$ machos y 8 hembras) provenientes de la Estación de Biología Chamela de la UNAM. La Estación está localizada en la costa suroeste del estado de Jalisco, México, en el municipio de La Huerta, en las coordenadas $19^{\circ} 30^{\prime} \mathrm{N}$ y $105^{\circ} 03^{\prime}$ $\mathrm{O}$ (Fig. 1). El clima es del tipo cálido subhúmedo con temperatura media anual de $24.6^{\circ} \mathrm{C}$ y $788 \mathrm{~mm}$ de precipitación promedio anual, concentrada en los meses de julio a octubre, por lo que su fórmula climática sería $\mathrm{A} w_{0} i$ (García-Oliva et al., 2002). La vegetación dominante es de bosque tropical caducifolio, que es la de mayor representación en la vertiente del Pacífico de México, desde el sur de Sonora hasta Chiapas (Rzedowski, 1978). La región de Chamela en Jalisco es una de las zonas con este tipo de vegetación mejor estudiada en América (González-Soriano et al., 2004) y su diversidad biológica es relativamente bien conocida.

Los alacranes fueron recolectados durante el día, por rodamiento de piedras y búsqueda en hendiduras y objetos en el suelo. También se hicieron recolecciones nocturnas utilizando lámparas con luz U.V. Se tienen ejemplares recolectados de plantas epífitas bromeliáceas (Tillandsia

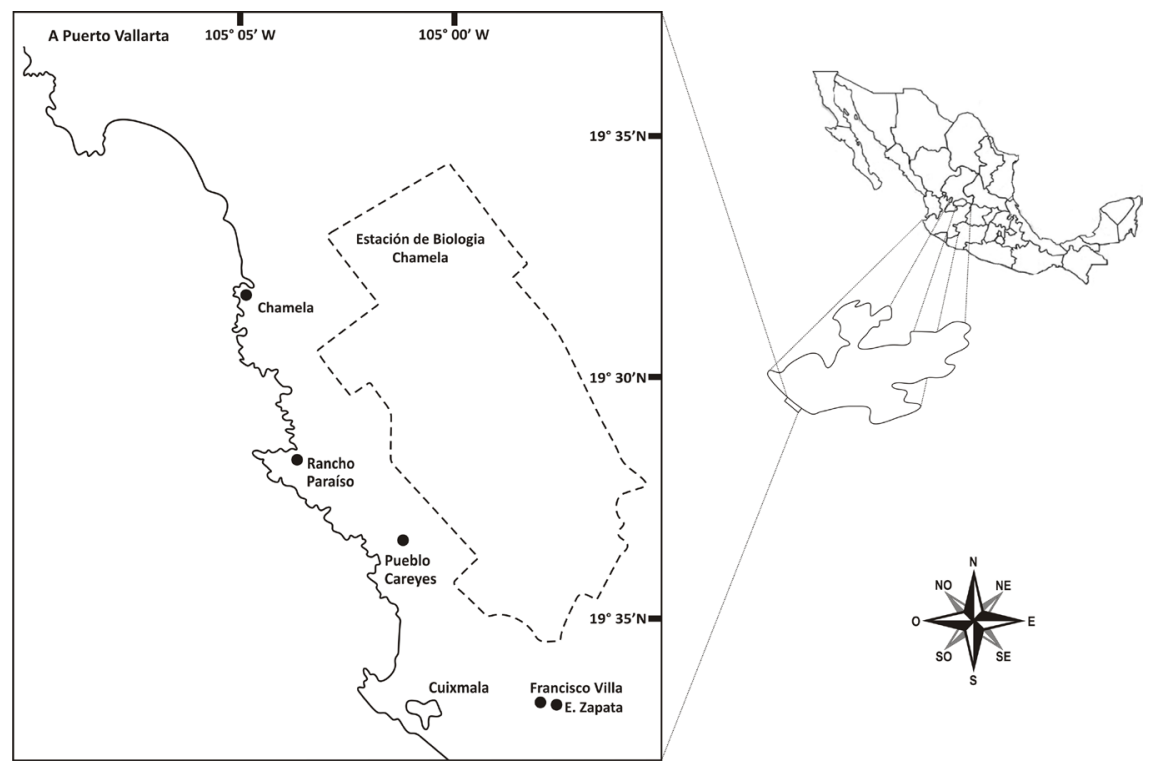

Figura 1. Ubicación de la localidad tipo. 
Cuadro 1. Especies de alacranes registradas para Jalisco, México

\begin{tabular}{|c|c|c|c|}
\hline Familia & Especie & Subespecie & Fuente \\
\hline \multirow[t]{7}{*}{ Buthidae } & $\begin{array}{l}\text { Centruroides bertholdii } \\
\text { (Thorell) }\end{array}$ & & $\begin{array}{l}\text { Hoffmann, 1932; Hoffmann, 1938; Díaz-Nájera, 1975; } \\
\text { Beutelspacher, 2000; Fet et al., 2000; Lourenço y Sissom, } \\
\text { 2000; González-Santillán, 2001; Ponce-Saavedra y Moreno, } \\
\text { 2005. }\end{array}$ \\
\hline & C. elegans (Thorell) & $\begin{array}{l}\text { C. elegans elegans } \\
\text { (Thorell) }\end{array}$ & $\begin{array}{l}\text { Hoffmann, 1932; Hoffmann, 1938; Díaz-Nájera, 1975; } \\
\text { Williams, 1986; Beutelspacher, 2000; Fet et al., 2000; } \\
\text { Lourenço y Sissom, 2000; González-Santillán, 2001; } \\
\text { González-Santillán, 2004; Ponce-Saavedra y Moreno, } 2005 .\end{array}$ \\
\hline & $\begin{array}{l}\text { C. infamatus (C. L. } \\
\text { Koch) }\end{array}$ & & González-Santillán, 2001. \\
\hline & C. ornatus Pocock & & $\begin{array}{l}\text { Hoffmann, 1932; Hoffmann, 1938; Díaz-Nájera, 1975; } \\
\text { Beutelspacher, 2000; Fet et al., 2000; Lourenço y Sissom, } \\
\text { 2000; González-Santillán, 2001; Ponce-Saavedra y Moreno, } \\
\text { 2005. }\end{array}$ \\
\hline & C. pallidiceps Pocock & & Beutelspacher, 2000. (Dudoso?) \\
\hline & C. tecomanus Hoffmann & & Beutelspacher, 2000. (Dudoso?) \\
\hline & $\begin{array}{l}\text { C. mascota } \text { Ponce- } \\
\text { Saavedra y Francke }\end{array}$ & & Ponce-Saavedra y Francke, 2011 \\
\hline \multirow[t]{8}{*}{ Vaejovidae } & $\begin{array}{l}\text { Vaejovis chamelaensis } \\
\text { Williams }\end{array}$ & & $\begin{array}{l}\text { Williams, 1986; Beutelspacher, 2000; Fet et al., 2000; } \\
\text { Lourenço y Sissom, 2000; González-Santillán, 2001; } \\
\text { González-Santillán, } 2004 .\end{array}$ \\
\hline & V. intermedius Borelli & & Beutelspacher, 2000. \\
\hline & V. intrepidus Thorell & $\begin{array}{l}\text { V. intrepidus atrox } \\
\text { Hoffmann }\end{array}$ & Beutelspacher, 2000; González-Santillán, 2001. \\
\hline & & $\begin{array}{l}\text { V. intrepidus } \\
\text { cristimanus Pocock }\end{array}$ & $\begin{array}{l}\text { Williams, 1986; Beutelspacher, 2000; Fet et al., 2000; } \\
\text { Lourenço y Sissom, 2000; González-Santillán, 2001; } \\
\text { González-Santillán, } 2004 .\end{array}$ \\
\hline & & $\begin{array}{l}\text { V. intrepidus intrepidus } \\
\text { Thorell }\end{array}$ & Beutelspacher, 2000; González-Santillán, 2001. \\
\hline & V. monticola Sissom & & $\begin{array}{l}\text { Sissom, 1989; Fet et al., 2000; Beutelspacher, 2000; } \\
\text { Lourenço y Sissom, 2000; González-Santillán, } 2001 .\end{array}$ \\
\hline & V. nigrescens Pocock & & $\begin{array}{l}\text { Beutelspacher, 2000; Fet et al., 2000; Lourenço y Sissom, } \\
\text { 2000; González-Santillán, 2001. }\end{array}$ \\
\hline & V. punctatus Karsch & $\begin{array}{l}\text { V. punctatus spadix } \\
\text { Hoffmann }\end{array}$ & $\begin{array}{l}\text { Beutelspacher, 2000; Fet et al., 2000; Lourenço y Sissom, } \\
\text { 2000; González-Santillán, } 2001 .\end{array}$ \\
\hline Diplocentridae & $\begin{array}{l}\text { Diplocentrus gertschi } \\
\text { Sissom y Walker }\end{array}$ & & $\begin{array}{l}\text { Beutelspacher, 2000; Fet et al., 2000; Lourenço y Sissom, } \\
\text { 2000; González-Santillán, 2001. }\end{array}$ \\
\hline
\end{tabular}

fasciculata Sw. y T. makoyana Baker) en diferentes fechas (véase lista de materiales tipo). Los ejemplares se sacrificaron por choque térmico y se conservaron en alcohol etílico al $75 \%$. Para la comparación directa con C. elegans, se utilizaron 6 ejemplares adultos ( 2 machos y 4 hembras) procedentes de la misma área. Se midieron las mismas características en ambas especies y se hizo la observación morfológica pertinente. Todos los ejemplares se revisaron con un microscopio estereoscópico Stemi DV4, se midieron con un Vernier Mitutoyo con $0.01 \mathrm{~mm}$ de precisión y se hizo el conteo de los dientes pectinales para obtener la variación morfológica y morfométrica de la especie. Se describieron siguiendo la nomenclatura y mediciones de Stahnke (1970), excepto en las carenas metasomales para las que se siguió a Francke (1977) y la terminología tricobotrial para la cual se utilizó la propuesta por Vachon (1974, 1975). Para las comparaciones estadísticas se utilizó la prueba de T de Student, aplicada con el programa JMP v6.0 de SAS Institute y los resultados se dan en términos de media y desviación estándar. 
El material estudiado quedó depositado en las siguientes colecciones: Colección Nacional de Arácnidos del Instituto de Biología de la Universidad Nacional Autónoma de México (CNAN), American Museum of Natural History, Nueva York, (AMNH), Instituto Nacional de Referencia Epidemiológica, México, D. F. (INDRE) y la colección de alacranes de la Facultad de Biología de la Universidad Michoacana de San Nicolás de Hidalgo, Morelia (CAFBUM).

\section{Centruroides chamela sp. nov.}

Centruroides sp. aff. elegans: González-Santillán 2004:29. Resumen taxonómico

Material tipo. MÉXICO: Jalisco: Chamela-Cuixmala, municipio de La Huerta.

Holotipo macho (CNAN-T0689). Recolectado sobre el suelo. Estación de Biología (IBUNAM) Chamela-Cuixmala, municipio de La Huerta, Jalisco, México. $19^{\circ} 29.875^{\text {' }}$ N; $105^{\circ} 02.608^{\prime}$ O, 97 m snm, 31-VIII-2007, O. Francke, A. Valdez, H. Montaño, A. Ballesteros y C. Santibáñez. Paratipos: 2 machos de la Colección Nacional de Arácnidos (CNAN-S01506), recolectados en bromelias, Estación Biológica de Chamela, Jalisco, 2-IV-1989, E. Ramírez; 2 hembras de la Colección Nacional de Arácnidos (CNANS01506), recolectadas en bromelias, Estación Biológica de Chamela, Jalisco, 2-IV-1989, E. Ramírez; 2 machos adultos y 2 hembras, recolectadas en bromeliáceas (AMNH), Estación Biológica de Chamela, Jalisco, 2-IV-1989, E. Ramírez; 2 machos adultos (INDRE), recolectados en bromeliáceas. Estación Biológica de Chamela, Jalisco, 2-IV-1989, E. Ramírez. 1 hembra (INDRE) recolectada en bromelia. Estación Biológica de Chamela, Jalisco, 2-IV1989, E. Ramírez. 1 hembra (INDRE), 1 macho y 1 hembra (FBUMSNH) recolectados sobre el suelo con lámpara UV en la misma localidad del holotipo en la misma fecha y por mismos recolectores. 1 macho (FBUMSNH) recolectado con lámpara UV, Estación Biológica de Chamela, Jalisco, camino a Chachalacas, sin fecha ni colector. $19^{\circ} 29.620^{\prime}$ N; $105^{\circ} 02.749^{\prime} \mathrm{O}$.

Etimología. El nombre específico se refiere a la localidad tipo. Se utiliza como un sustantivo en aposición.

Distribución. Actualmente sólo se conoce para la localidad tipo.

Descripción del holotipo (macho adulto). Tamaño pequeño a mediano. Quela del pedipalpo de apariencia relativamente alargada con dedo fijo casi de la misma longitud de mano y dedo móvil 1.29 veces más largo (Cuadro 2). Con 8 hileras imbricadas de dientes medios (incluyendo la pequeña hilera distal de 4 dientecillos en el dedo móvil y 5 en el fijo); externamente, dedo móvil con 3 dientes accesorios basales pequeños y el resto alternando dientes grandes con una serie de 2 dientes medianos y 2 pequeños hasta formar 7 series de dientes accesorios. Conteo de dientes pectíneos de 18-18 y la placa base de los peines el doble de ancho que el largo. Longitud corporal 1.5 veces la longitud del metasoma. Para todas las medidas, véase Cuadro 2.

Coloración. Color base amarillo, un poco más obscuro dorsalmente. Con manchas sobre tergitos del mesosoma, las cuales forman 2 bandas obscuras separadas por una área mesal sin pigmento, ligeramente más angosta que las bandas obscuras. Carapacho con 4 líneas longitudinales bien definidas, las 2 centrales sobre las carenas medias anteriores pasando a los lados del surco medio anterior hasta las carenas oculares y continuando en la zona de las carenas marginales anteriores, más delgadas en la mitad posterior del carapacho y prolongándose hasta antes del surco marginal posterior, sin alcanzar el borde posterior del carapacho. Líneas externas, con pigmentación muy débil al inicio, en el área de los ojos laterales, haciéndose evidentes casi a la altura de los ojos medios y pasando por las carenas oculares laterales y las laterales posteriores, donde son de color más intenso, hasta llegar al surco marginal posterior. Área de los ojos laterales pigmentada, alrededor de los ojos medios, muy intensa. Superficie entre las líneas sin pigmento, sólo se observa ligeramente sombreada. Bandas obscuras recorren longitudinalmente el mesosoma con pigmento, tanto en el pretergito como en el postergito, excepto en postergitos I y II en los que la mancha basal no está bien definida. Bandas formadas por una mancha muy obscura en pretergito, que continúa con pigmentación de apariencia reticulada hasta unirse con otra mancha muy obscura en el postergito cuya forma es claramente más delgada que la del pretergito. Mancha del pretergito rectangular, muy delgada en pretergitos I y II y gradualmente más gruesa en tergitos posteriores. Mancha posterior tenue en tergitos I y II y de forma ligeramente redondeada, más obscura, gruesa y uniforme en tergitos III-VI (Fig. 2d). Bordes laterales con pigmento bien definido en la mitad anterior de placas I y II, pero a partir de la placa III la intensidad del pigmento disminuye hasta que en las placas V, VI y VII el borde es completamente claro. Tergito VII sólo bien pigmentado en pretergito; mientras que en el postergito la mancha es pequeña, triangular y con pigmentación menos intensa que se une a las carenas laterales dando la apariencia de 2 líneas que se adelgazan hacia el borde posterior, pero que en el extremo vuelven a engrosarse ligeramente (Fig. 2d). Metasoma de coloración similar al resto del cuerpo, con la superficie dorsal sin pigmento, mientras que las zonas laterales y ventrales presentan pigmentación ligera sobre las carenas. En telson, vesícula en su mayoría amarilla y el aguijón más obscuro. Pedipalpos de coloración uniforme, igual al resto del cuerpo, sólo con tenues manchas de pigmento sobre la cara dorsal del fémur, patela y mano. Patas 
Cuadro 2. Medidas tomadas al material tipo de Centruroides chamela sp. nov.

\begin{tabular}{|c|c|c|c|c|c|c|c|c|c|}
\hline \multicolumn{10}{|c|}{ Paratipos macho (medidas en mm) } \\
\hline Medidas tomadas/machos & Holotipo & PMI & PM2 & PM3 & PM4 & PM5 & PM6 & PM7 & PM8 \\
\hline $\begin{array}{l}\text { Carapacho (Largo/Ancho posterior/ } \\
\text { Ancho anterior) }\end{array}$ & $4.29 / 4.11 / 3.28$ & $4.22 / 4.19 / 3.30$ & $4.06 / 4.04 / 3.33$ & $3.94 / 3.94 / 3.10$ & $3.71 / 3.40 / 2.79$ & $4.37 / 4.09 / 3.23$ & $4.06 / 3.91 / 3.05$ & $4.17 / 4.06 / 3.2$ & $3.78 / 3.68 / 2.87$ \\
\hline $\begin{array}{l}\text { Long. del mesosoma incluyendo } \\
\text { SMVII }\end{array}$ & 11.40 & 12.09 & 13.03 & 10.72 & 10.67 & 11.89 & 10.64 & 12.90 & 10.95 \\
\hline Conteo pectinal & $18-18$ & $18-18$ & $18-19$ & $19-19$ & $18-19$ & $20-20$ & $17-17$ & 18-19 & $19-20$ \\
\hline Segmento caudal I (Largo/Ancho) & $3.86 / 2.16$ & $3.96 / 2.13$ & $3.86 / 2.08$ & $3.61 / 2.01$ & $3.51 / 1.91$ & $3.81 / 2.06$ & $3.86 / 2.08$ & $4.04 / 2.16$ & $3.40 / 2.03$ \\
\hline Segmento caudal II (Largo/Ancho) & $4.85 / 2.03$ & $4.90 / 2.06$ & $4.52 / 1.98$ & $4.39 / 1.91$ & $4.19 / 2.08$ & $5.08 / 2.11$ & $4.65 / 2.01$ & $4.95 / 2.13$ & $4.11 / 1.91$ \\
\hline Segmento Caudal III (Largo/Ancho) & $5.21 / 2.01$ & $5.54 / 2.08$ & $5.12 / 2.03$ & $4.88 / 2.01$ & $4.67 / 1.91$ & $5.64 / 2.16$ & $5.16 / 2.06$ & $5.59 / 2.13$ & $4.62 / 1.85$ \\
\hline Segmento caudal IV (Largo/Ancho) & $5.72 / 2.16$ & $5.89 / 2.13$ & $5.83 / 2.01$ & $5.11 / 2.01$ & $4.98 / 1.83$ & $5.97 / 2.21$ & $5.44 / 2.11$ & $5.82 / 2.18$ & $4.72 / 1.78$ \\
\hline Segmento caudal V (Largo/Ancho) & $6.38 / 2.16$ & $6.12 / 2.11$ & $5.87 / 2.08$ & $5.46 / 2.01$ & $5.33 / 1.83$ & $5.98 / 2.26$ & $5.69 / 2.11$ & $6.10 / 2.18$ & $4.93 / 1.78$ \\
\hline Vesícula (Largo/Ancho/Alto) & $3.05 / 1.57 / 1.70$ & $3.10 / 1.70 / 1.63$ & $3.07 / 1.65 / 1.65$ & $2.82 / 1.60 / 1.55$ & $2.82 / 1.45 / 1.45$ & $3.25 / 1.68 / 1.78$ & $3.02 / 1.60 / 1.60$ & $3.12 / 1.70 / 1.70$ & $2.69 / 1.40 / 1.42$ \\
\hline Aguijón & 1.65 & 1.47 & 1.35 & 1.35 & 1.57 & 1.70 & 1.50 & 1.60 & 1.27 \\
\hline Long. metasoma incluyendo vesícula & 29.07 & 29.51 & 28.27 & 26.27 & 25.50 & 29.73 & 27.82 & 29.62 & 24.47 \\
\hline Fémur (Largo/Ancho) & $4.37 / 1.22$ & $4.50 / 1.19$ & $4.14 / 1.12$ & $4.17 / 1.24$ & $3.81 / 1.14$ & $4.45 / 1.30$ & $4.29 / 1.22$ & $4.32 / 1.22$ & $4.01 / 1.07$ \\
\hline Patela (Largo/Ancho) & $5.05 / 1.98$ & $5.16 / 1.91$ & $4.70 / 1.91$ & $4.65 / 1.75$ & $4.37 / 1.65$ & $5.08 / 1.85$ & $4.70 / 1.75$ & $4.85 / 1.78$ & $4.24 / 1.50$ \\
\hline Mano (Largo/Ancho/Alto) & $4.34 / 2.01 / 1.88$ & $4.09 / 2.08 / 1.98$ & $3.96 / 2.03 / 1.88$ & $3.73 / 1.91 / 2.16$ & $3.78 / 2.01 / 1.68$ & $4.27 / 2.08 / 1.88$ & $4.24 / 1.96 / 1.83$ & $4.11 / 1.93 / 1.91$ & $3.63 / 1.75 / 1.60$ \\
\hline Dedo fijo & 4.06 & 3.96 & 4.01 & 3.96 & 3.78 & 4.19 & 3.88 & 4.26 & 3.38 \\
\hline Dedo móvil & 5.23 & 5.00 & 4.83 & 4.85 & 4.24 & 5.26 & 4.75 & 5.23 & 4.81 \\
\hline Base de los peines (Largo/Ancho) & $0.53 / 0.94$ & $0.74 / 0.99$ & $0.76 / 0.99$ & $0.60 / 0.94$ & $0.56 / 0.80$ & $0.66 / 0.94$ & $0.48 / 0.79$ & $0.48 / 0.98$ & $0.51 / 0.79$ \\
\hline $\begin{array}{l}\text { Proporción L/A de la base de los } \\
\text { peines }\end{array}$ & 0.56 & 0.75 & 0.77 & 0.64 & 0.70 & 0.70 & 0.61 & 0.49 & 0.65 \\
\hline Proporción L corporal/L metasoma & 1.54 & 1.55 & 1.60 & 1.56 & 1.56 & 1.55 & 1.53 & 1.58 & 1.60 \\
\hline Longitud corporal & 44.77 & 45.82 & 45.36 & 40.93 & 39.88 & 45.99 & 42.53 & 46.69 & 39.20 \\
\hline \multicolumn{10}{|l|}{ Promedio: $43.99 \pm 2.55 \mathrm{~mm}$} \\
\hline Medidas tomadas/hembras & $p h 1$ & $p h 2$ & $p h 3$ & ph4 & $p h 5$ & ph6 & $p h 7$ & ph8 & \\
\hline $\begin{array}{l}\text { Carapacho (Largo/Ancho posterior/ } \\
\text { Ancho anterior) }\end{array}$ & $4.80 / 4.67 / 3.63$ & $4.24 / 4.52 / 3.48$ & $4.47 / 4.52 / 3.63$ & $4.45 / 4.52 / 3.56$ & $4.62 / 4.88 / 3.76$ & $4.67 / 4.60 / 3.61$ & $4.78 / 4.90 / 3.56$ & $4.24 / 4.29 / 3.30$ & \\
\hline $\begin{array}{l}\text { Long. del mesosoma incluyendo } \\
\text { SMVII }\end{array}$ & 15.09 & 13.13 & 12.98 & 12.55 & 14.50 & 11.51 & 15.24 & 12.07 & \\
\hline Conteo pectinal & $17-18$ & $17-17$ & $16-16$ & $17-17$ & $17-17$ & $17-15$ & $17-16$ & $16-16$ & \\
\hline Segmento caudal I (Largo/Ancho) & $3.63 / 2.57$ & $3.05 / 2.34$ & $3.45 / 2.44$ & $3.40 / 2.46$ & $3.45 / 2.62$ & $3.23 / 2.57$ & $3.51 / 2.46$ & $3.15 / 2.26$ & \\
\hline Segmento caudal II (Largo/Ancho) & $4.37 / 2.51$ & $3.78 / 2.16$ & $4.17 / 2.29$ & $4.22 / 2.36$ & $4.19 / 2.41$ & $4.01 / 2.39$ & $4.17 / 2.34$ & $3.89 / 2.21$ & \\
\hline Segmento caudal III (Largo/Ancho) & $4.70 / 2.41$ & $4.19 / 2.13$ & $4.39 / 2.31$ & $4.39 / 2.31$ & $4.52 / 2.36$ & $4.42 / 2.41$ & $4.42 / 2.39$ & $4.24 / 2.13$ & \\
\hline Segmento Caudal IV (Largo/Ancho) & $5.05 / 2.41$ & $4.37 / 2.13$ & $4.78 / 2.24$ & $4.80 / 2.29$ & $4.70 / 2.31$ & $4.67 / 2.39$ & $4.90 / 2.41$ & $4.57 / 2.08$ & \\
\hline Segmento caudal V (Largo/Ancho) & $5.56 / 2.39$ & $4.93 / 2.03$ & $5.26 / 2.26$ & $5.28 / 2.26$ & $5.21 / 2.29$ & $5.08 / 2.34$ & $5.26 / 2.41$ & $4.88 / 1.98$ & \\
\hline Vesícula (Largo/Ancho/Alto) & $2.95 / 1.63 / 1.65$ & $2.29 / 1.50 / 1.57$ & $2.79 / 1.70 / 1.73$ & $2.84 / 1.68 / 1.65$ & $2.79 / 1.73 / 1.88$ & $2.77 / 1.68 / 1.65$ & $3.00 / 1.60 / 1.78$ & $2.54 / 1.98 / 1.52$ & \\
\hline Aguijón & 1.80 & 1.78 & 1.70 & 1.70 & 1.85 & 2.26 & 1.85 & 1.73 & \\
\hline $\begin{array}{l}\text { Long. metasoma incluyendo } \\
\text { vesícula }\end{array}$ & 26.26 & 22.61 & 24.84 & 24.93 & 24.78 & 24.18 & 25.26 & 23.27 & \\
\hline Fémur (Largo/Ancho) & $4.70 / 1.57$ & $4.09 / 1.37$ & $4.45 / 1.27$ & $4.24 / 1.37$ & $4.45 / 1.45$ & $4.39 / 1.35$ & $4.50 / 1.35$ & $4.17 / 1.22$ & \\
\hline Patela (Largo/Ancho) & $5.49 / 2.16$ & $4.80 / 1.91$ & $5.21 / 1.91$ & $4.98 / 1.98$ & $5.11 / 2.16$ & $5.16 / 2.03$ & $5.18 / 2.03$ & $4.75 / 1.80$ & \\
\hline Mano (Largo/Ancho/Alto) & $4.52 / 2.21 / 2.13$ & $3.66 / 1.85 / 1.75$ & $4.19 / 2.01 / 2.24$ & $4.19 / 2.03 / 1.80$ & $3.99 / 2.03 / 1.96$ & $4.14 / 2.06 / 1.80$ & $4.29 / 2.11 / 1.91$ & $3.84 / 1.83 / 1.73$ & \\
\hline Dedo fijo & 4.77 & 4.52 & 4.49 & 4.05 & 4.65 & 4.31 & 4.62 & 4.21 & \\
\hline Dedo móvil & 5.84 & 5.21 & 5.69 & 5.28 & 5.59 & 5.54 & 5.61 & 5.23 & \\
\hline Base de los peines (Largo/Ancho) & $0.69 / 1.35$ & $0.71 / 1.34$ & $0.61 / 1.14$ & $0.51 / 1.04$ & $0.58 / 1.09$ & $0.76 / 1.17$ & $0.64 / 1.22$ & $0.53 / 1.09$ & \\
\hline $\begin{array}{l}\text { Proporción } L / A \text { de la base de los } \\
\text { peines }\end{array}$ & 0.51 & 0.53 & 0.54 & 0.49 & 0.53 & 0.65 & 0.52 & 0.49 & \\
\hline Proporción L corporal/ L metasoma & 1.76 & 1.77 & 1.70 & 1.68 & 1.77 & 1.67 & 1.79 & 1.70 & \\
\hline Longitud corporal & 46.15 & 39.98 & 42.29 & 41.92 & 43.91 & 40.36 & 45.28 & 39.58 & \\
\hline Promedio: $42.43 \pm 2.47 \mathrm{~mm}$ & & & & & & & & & \\
\hline
\end{tabular}


de color claro con pequeñas manchas rojizas en articulaciones fémur-patela, patela-tibia y tibia-basitarso.

Otras características morfológicas y superficie cuticular. Prosoma. Carapacho con borde anterior cóncavo y moderadamente crenulado. Bordes laterales finamente crenulados. Carenas medias anteriores, superciliares, oculares laterales, medias centrales, posteriores y laterales presentes con granulación fina y rala. Superficie adyacente lisa, con escasa granulación sobre las manchas de pigmento (Fig. 2a). En esternón setas pequeñas e inconspicuas.

Mesosoma. Tergitos con bordes posteriores y zona pigmentada de postergitos con granulación escasa. Carena media granulosa, apreciable en los postergitos II-VI, alargándose hasta ocupar más de la mitad posterior de los postergitos V y VI, donde los gránulos están mejor definidos que en los tergitos anteriores; en el tergito VII los gránulos de la carena están menos definidos y son de menor tamaño (Fig. 2d). Ventralmente, los esternitos son lisos y brillantes. Placas genitales y esternitos con setas pequeñas e inconspicuas lo que les confiere una apariencia general lisa (Fig. 2c).

Metasoma. Carenas dorsales ligeramente dentadas y laterales superiores crenuladas a ligeramente dentadas, mejor desarrolladas en segmentos I y II y disminuyendo en segmentos III y IV hasta ser casi lisas en segmento caudal V (Fig. 2g). Carenas medias ventrales y ventrolaterales presentes en todos los segmentos, vestigiales en segmento I, lisas y poco aparentes en segmento II y en segmentos III-V bien desarrolladas y crenuladas. No hay setas bien desarrolladas en ninguno de los segmentos caudales.

Telson. Vesícula ligeramente alargada con tubérculo subaculear cónico pero poco desarrollado (Fig. 2f).

Pedipalpos. Delgados, esbeltos y con manos delicadas, 2.16 veces más largas que anchas y casi tan altas como anchas (proporción largo/alto $=1.07$ ); ambos dedos largos, con el dedo fijo más pequeño que el móvil (Cuadro 2). Mano de la quela con carenas lisas poco desarrolladas o vestigiales, excepto la secundaria exterior, la digital (que no se extiende hacia el dedo fijo) y la secundaria interna que son ligeramente crenuladas (un poco mejor desarrolladas en las hembras) (Fig. 3e). Tanto en el fémur como en la patela, las carenas se observan bien desarrolladas pero tienen pocas setas y granulaciones (Figs. 3a-d). Superficie de los dedos móvil y fija, completamente lisa. Patrón tricobotrial característico del género, ortobotriotáxico tipo A-alfa.

Peines. Base de los peines presenta en el borde anterior escotadura media bien definida y el borde posterior casi recto, muy ligeramente rebordeado (Figs. 2b, 5).

Patas. Color uniforme, más claro que el prosoma y mesosoma en vista dorsal. Se observa una pequeña mancha café rojiza en extremo distal del fémur y de la patela, justo en la articulación.
Variación y dimorfismo sexual. Tamaño pequeño a mediano de 39.20-46.69 $\mathrm{mm}$ en machos adultos $(\mathrm{n}=9$, promedio= $43.99 \pm 2.55)$ y $47.75-50.55 \mathrm{~mm}$ en hembras ( $\mathrm{n}=8$, promedio $=42.43 \pm 2.47)$ sin que exista diferencia estadística $(\mathrm{t}=$ $0.92 ; p=0.368)$. Número de dientes pectíneos, en machos varía de 17 a $20(n=18$ peines $)$ con moda en $18(38.9 \%)$ y 19 (33.3\%), mientras que en hembras varía de $15(6.25 \%)$ a $18(6.25 \%)$ con moda $=17(56.25 \%)$. Vesícula del telson de machos estadísticamente más larga $(2.99 \pm 0.23)$ que la de hembras $(2.75 \pm 0.05)(\mathrm{t}=2.30 ; p=0.036 ; \mathrm{n}=$ 8 hembras y 9 machos). Segmentos caudales más largos en machos y más anchos en hembras (véase Cuadro 2). La diferencia en la proporción entre la longitud y el ancho de la base de los peines en uno y otro sexo es estadísticamente significativa $(\mathrm{t}=2.83 ; p=0.01)$; en los machos es de $0.65 \pm 0.09(\mathrm{n}=9) \mathrm{y}$ en las hembras de $0.53 \pm 0.05$ $(\mathrm{n}=8)$, lo que refleja dimorfismo; también la forma de la pieza basal presenta diferencias entre ambos sexos, ya que el borde posterior de la base de los peines de la hembra es claramente redondeado (Figs. 5, 6), mientras que el del macho sólo es muy ligeramente rebordeado; además en los machos, la escotadura media está bien definida y no así en las hembras (Fig. 4). La proporción longitud/ancho de la vesícula también mostró diferencias estadísticas significativas ( $\mathrm{t}=5.28 ; p<0.0001)$ con un valor promedio de $1.88 \pm 0.06$ para los machos y de $1.64 \pm 0.18$ para las hembras, lo que se traduce en una vesícula más larga y esbelta en los machos. Tubérculo subaculear poco desarrollado en algunos machos, dando apariencia de ser romo. La pigmentación en pedipalpos, tanto en hembras como en machos, puede ser ligera pero evidente o estar ausente, sobre todo en las manos.

Diagnosis comparativa. Centruroides chamela es una especie del grupo de los "rayados" sensu González-Santillán (2001), con el dimorfismo sexual característico de los integrantes del género Centruroides (Hoffman, 1932), lo que se refleja en la proporción de la longitud corporal con respecto a la longitud del metasoma, la cual tiene un valor promedio de $1.56 \pm 0.02$ en los machos, y es mayor en la hembra (1.73 \pm 0.05$)$ (Cuadro 2). La superficie del carapacho es lisa, si hay gránulos son finos, bien definidos y muy poco densos, a diferencia de lo observado en $C$. hirsutipalpus Ponce-Saavedra y Francke, C. elegans y $C$. meisei Hoffmann, cuyos gránulos dispersos son grandes, y aunque poco densos, evidentes. Difiere también de $C$. tecomanus porque en esta especie el carapacho es claramente granuloso y los granos mucho más densos. Las especies registradas para los estados de Colima, Jalisco y Nayarit que pudieran confundirse con $C$. chamela sp. nov., presentan diferencias morfológicas que permiten su identificación sin problema. Puede diferenciarse de $C$. bertholdii por el patrón general de pigmentación de esta 

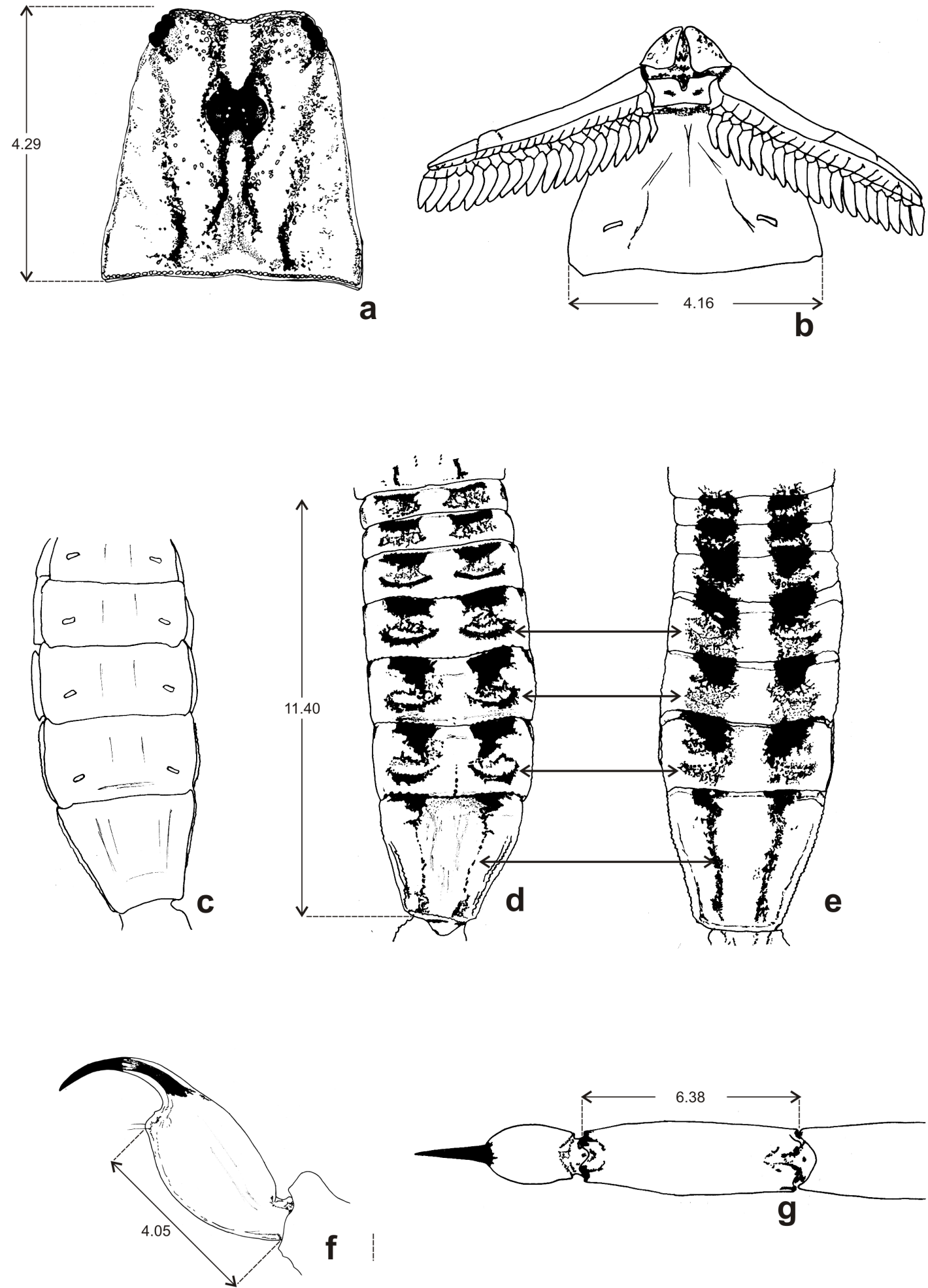

Figura 2. Características morfológicas de Centruroides chamela sp. nov. (macho). a, caparazón cefalotorácico o carapacho; b, vista ventral mostrando base de peines, peines, placas genitales y primer esternito; c, vista ventral del mesosoma; d, vista dorsal del mesosoma de C. chamela mostrando patrón de coloración; e, vista dorsal del mesosoma de C. elegans mostrando patrón de coloración; f, vista lateral de la vesícula y el aguijón mostrando el poco desarrollo del tubérculo subaculear; g, vista dorsal del segmento caudal V, vesícula y aguijón. Medidas en mm. 

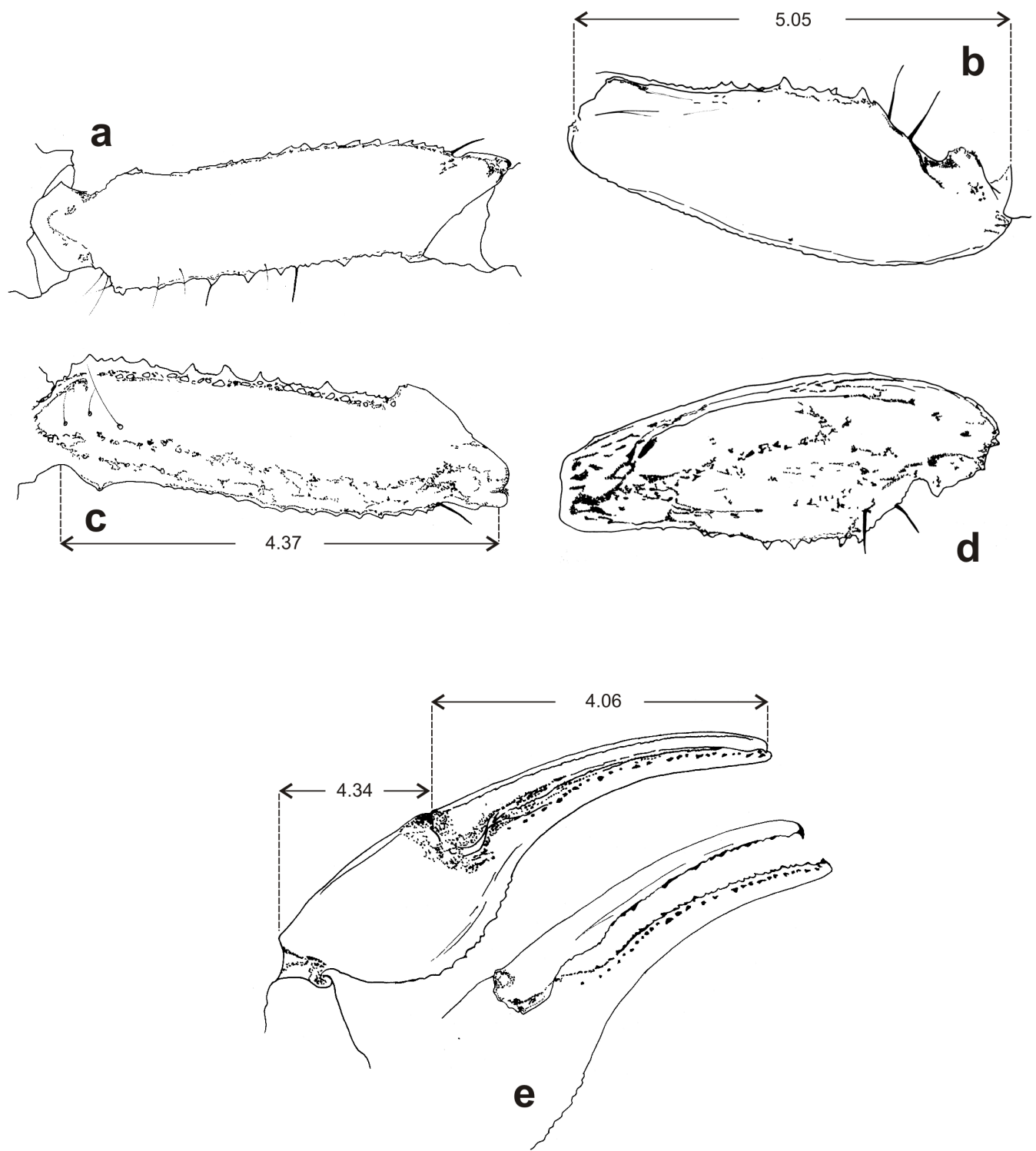

Figura 3. Otras características morfológicas de Centruroides chamela sp. nov. Vistas dorsal y ventral del fémur (a, c) y patela (b, d) del pedipalpo. Vista dorsal y ventral de la mano del pedipalpo (e). Medidas en mm.

especie, el cual es uniforme y sin bandas longitudinales aparentes, característica suficiente para distinguirla de la especie nueva que pertenece al grupo "rayados". Puede diferenciarse de $C$. infamatus y $C$. ornatus por el patrón de coloración del carapacho que en estas especies no presenta líneas definidas sino que está coloreado de manera difusa a muy obscura en la mayor parte de la superficie, lo suficiente como para diferenciarlos y ubicarlos en subgrupos distintos dentro del grupo "rayados" (Santibáñez-López y Ponce-Saavedra, 2009).

Se conocen además otras 4 especies con características de coloración similares; 3 de éstas, C. mascota, $C$. hirsutipalpus y C. tecomanus se encuentran relativamente cercanas a la localidad tipo de C. chamela sp. nov., que puede diferenciarse de C. mascota, por el número de dientes pectíneos (22-22 para C. mascota), ornamentación de la cutícula, forma (Fig. 5) y proporción ancho/largo de la base de los peines que es mayor en C. mascota (1.96 contra 1.64) y por la evidente presencia de setas en los esternitos y segmentos metasomales que en $C$. chamela son poco visibles; C. mascota presenta además diferencias respecto al hábitat en el que se le encuentra; fue registrada para la región de Mascota, Jal., enclavada en la sierra Madre Occidental, con vegetación de bosque de pino en altitu- 

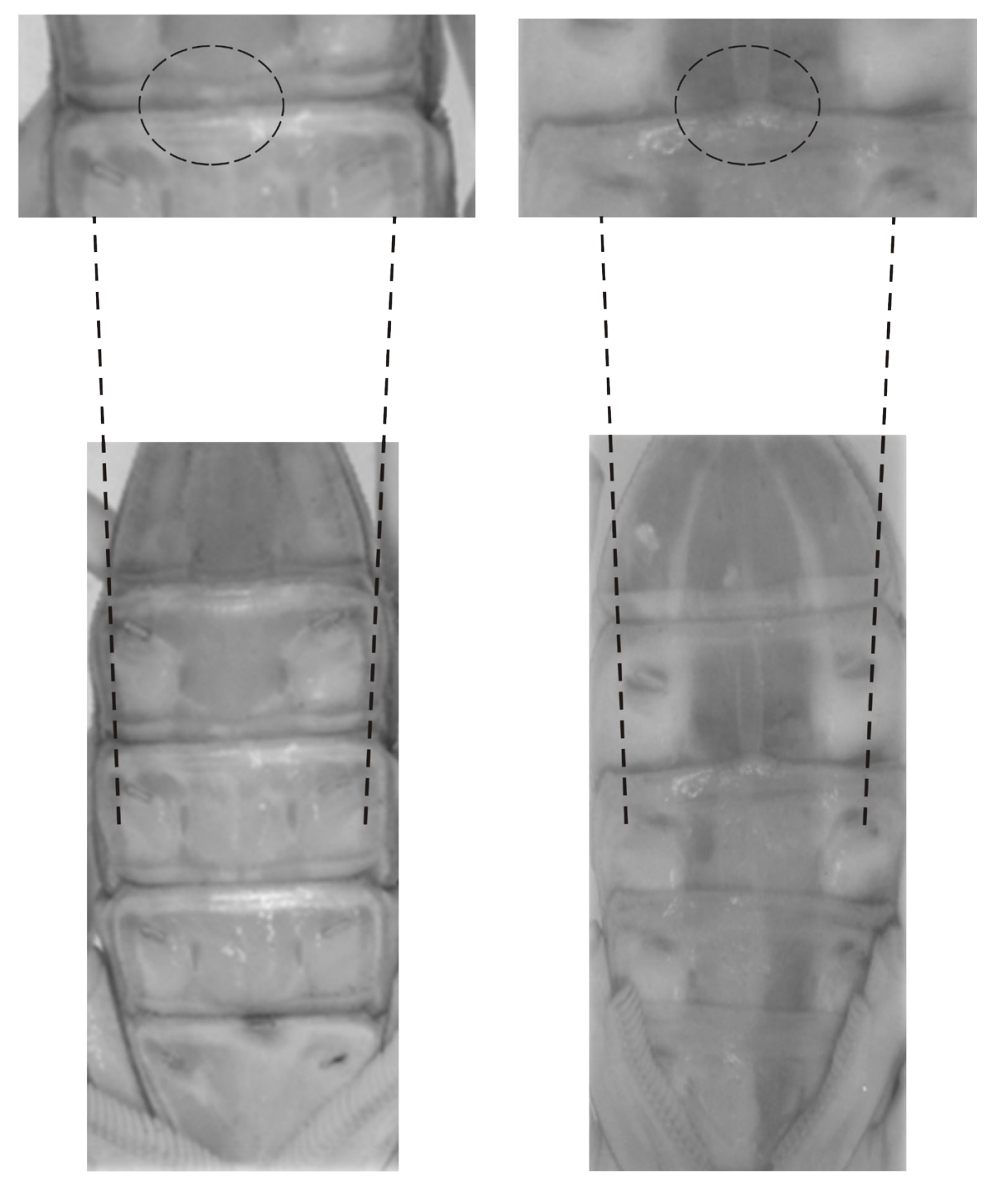

Figura 4. Margen posterior del esternito III, diferencia morfológica entre Centruroides chamela (izq.) y C. meisei (der.).

des cercanas a los 900 metros (Ponce-Saavedra y Francke, 2011).

En el caso de C. hirsutipalpus la diferencia más importante es el número de setas en el pedipalpo, ya que esta especie se caracteriza por tener 11-17 setas en la cara externa del fémur; 12-16 en la interna (9-10 grandes) y 12-15 setas en la cara superior de la patela (12-14 en las hembras); número que en C. chamela sp. nov. es claramente inferior (2-5 setas conspicuas), como ocurre con las otras especies del grupo de los "rayados" hasta ahora descritas. Adicionalmente, también es clara la diferencia en la base de los peines de los machos, que en la nueva especie es más rectangular y con una muesca media bien definida; mientras que en $C$. hirsutipalpus el borde anterior converge hacia el centro dando forma trapezoidal (Fig. 6). Centruroides tecomanus es morfológicamente bastante similar, pero también de mayor tamaño, los machos miden alrededor de $67 \mathrm{~mm}$ y las hembras $63 \mathrm{~mm}$ (Quijano-Ravell et al., 2010); presenta un tubérculo subaculear cónico bien desarrollado y con la punta del tubérculo orientada hacia la punta del aguijón, mientras que en $C$. chamela sp. nov. el tubérculo es poco desarrollado e incluso puede ser romo (Fig. 2f). La base de los peines de los machos también es ligeramente distinta en forma (Fig.5).

La distribución geográfica de C. chamela sp. nov. aporta evidencias sobre su identidad, ya que el área conocida se ubica sobre la costa de Jalisco, en simpatría con $C$. elegans, aunque sin superponerse con la distribución de $C$. tecomanus, registrada para Colima, Michoacán, Jalisco y recientemente para la costa de Guerrero (Quijano-Ravell et al., 2010).

Centruroides meisei, que por tamaño y apariencia general podría confundirse con la especie nueva, puede diferenciarse por el patrón de manchas en el mesosoma y sobre todo por la ligera lobulación que $C$. meisei presenta en el borde posterior del esternito III (Fig. 4), la que no está presente en la nueva especie, donde este borde es recto.

En el caso de C. elegans, al ser una especie simpátrica, se la comparó con mayor detenimiento y pudieron establecerse diferencias muy evidentes, como $a$ ), el patrón de coloración de las bandas que recorren dorsalmente el mesosoma, en C. elegans está formado por manchas de 


\section{Hembras}

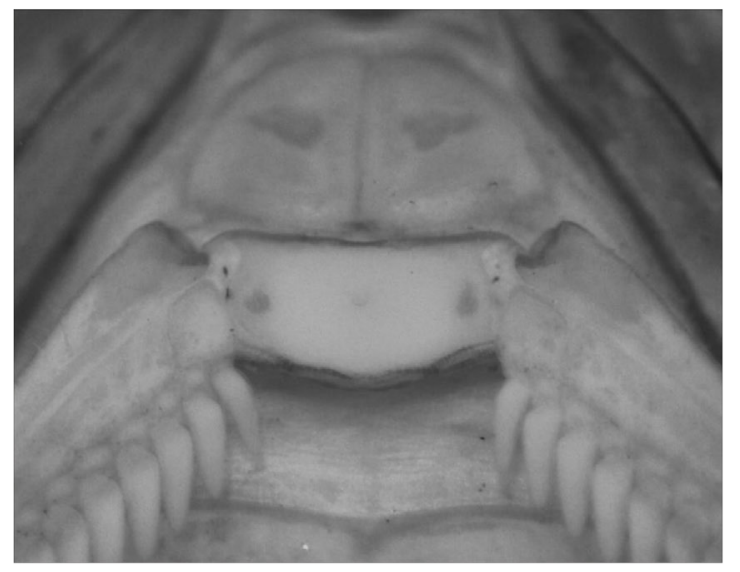

Machos

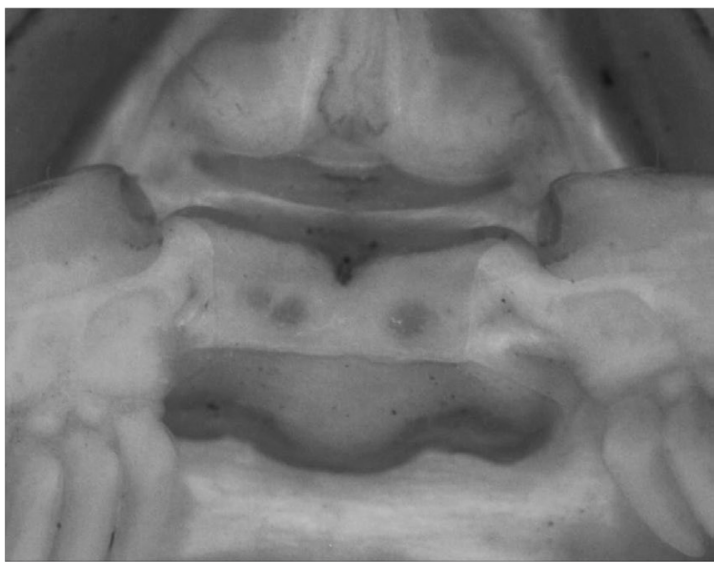

C. chamela
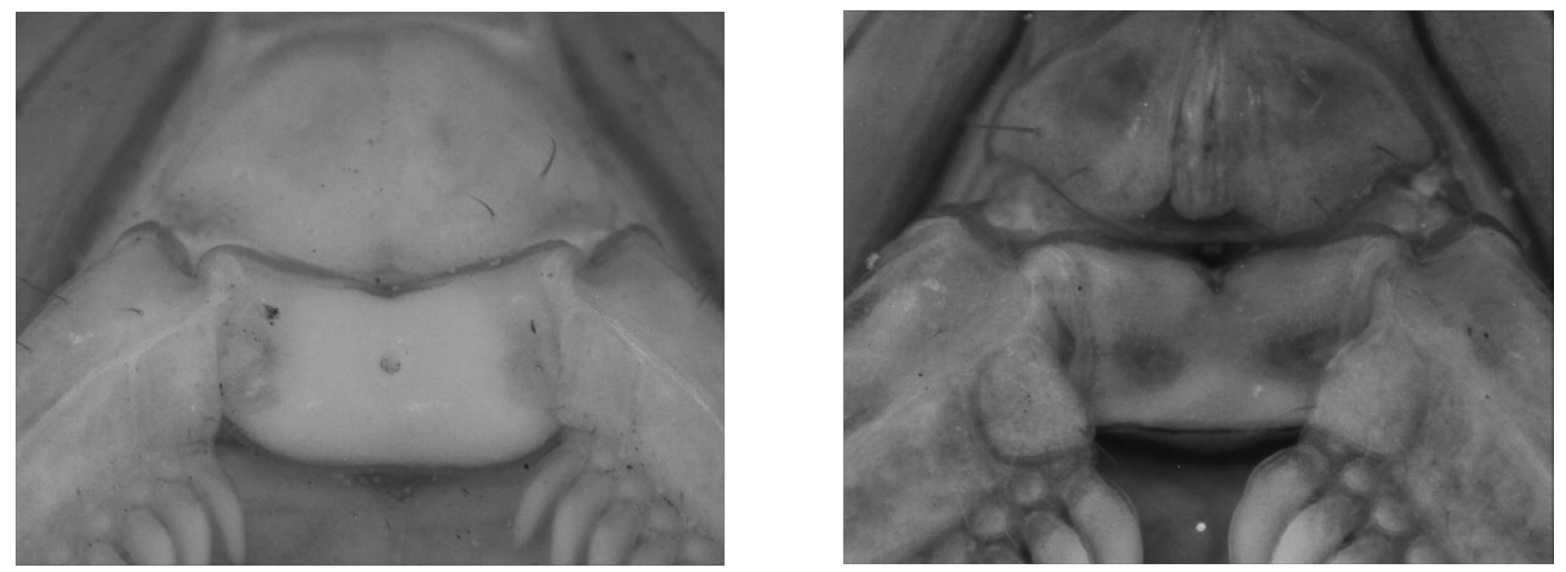

C. elegans
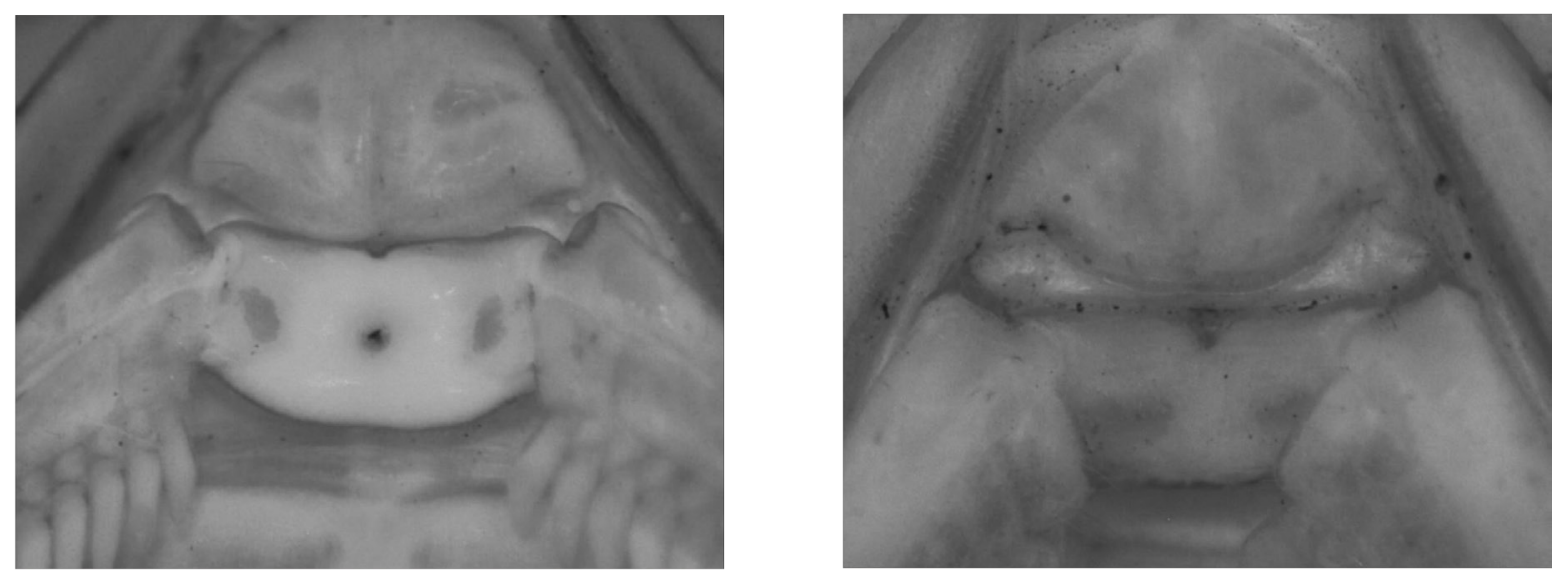

C. mascota

Figura 5. Comparación de la base de los peines de especies de Centruroides: C. chamela sp. nov., C. elegans, C. mascota. Hembras (izq.); machos (der.). 


\section{Hembras}

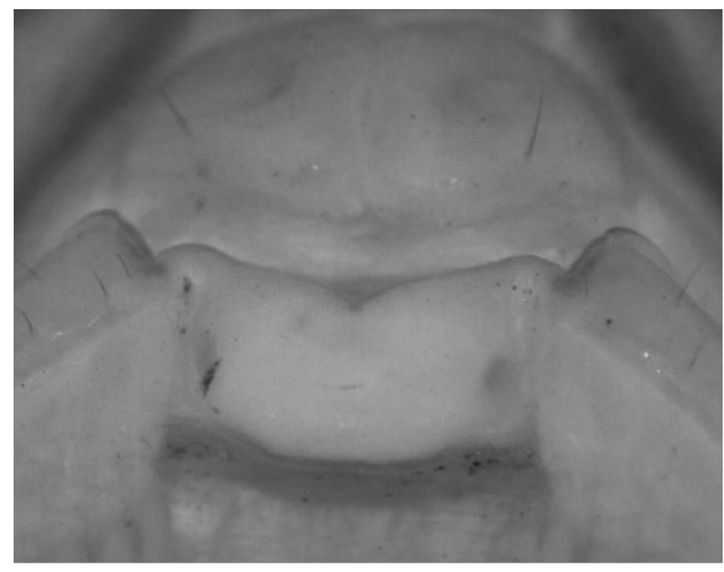

Machos

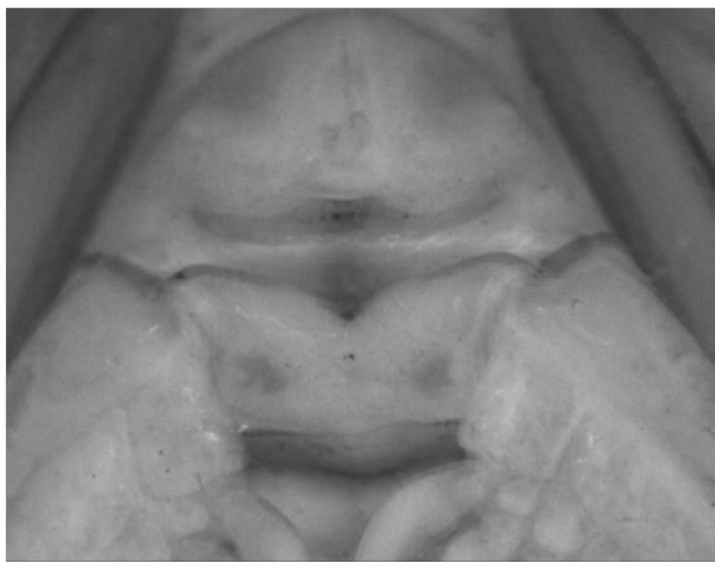

C. hirsutipalpus

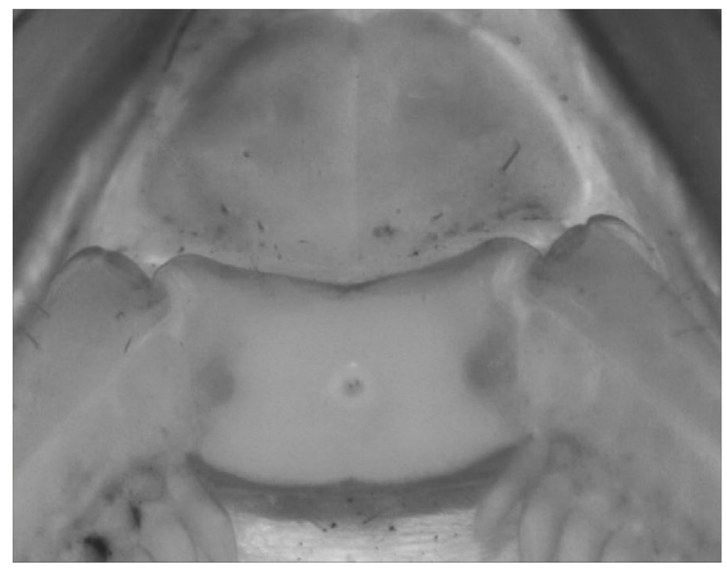

C. tecomanus
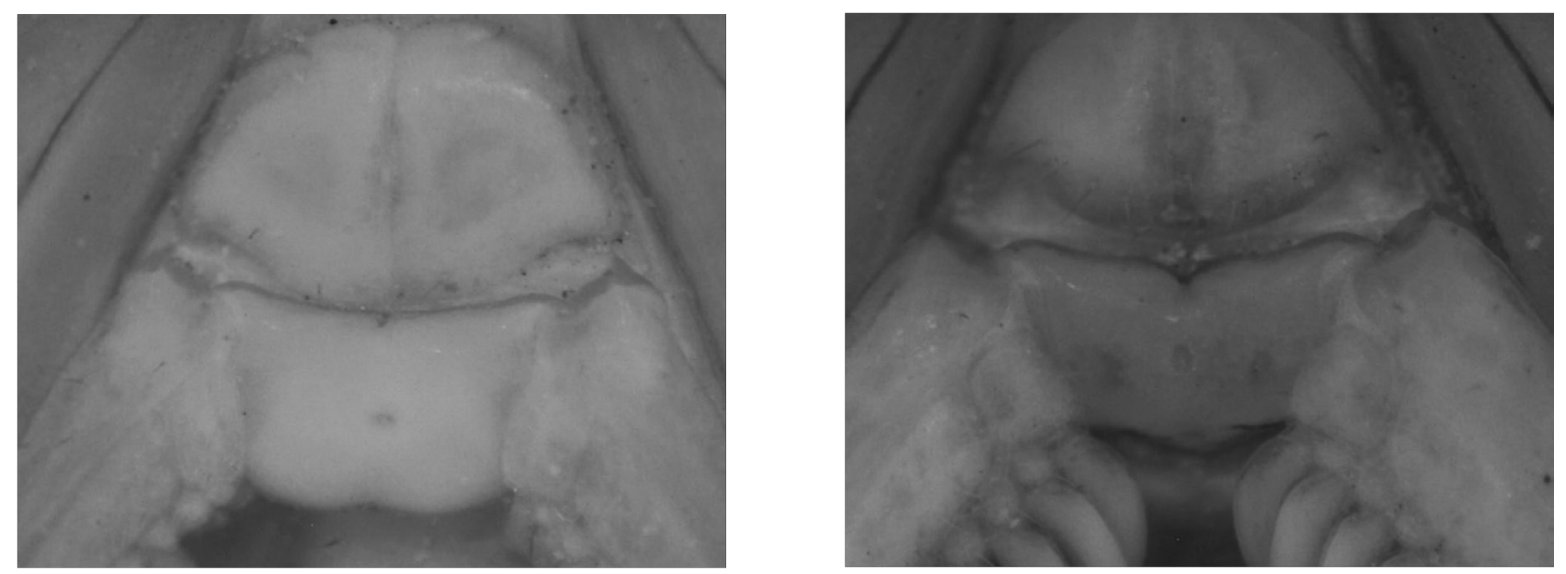

C. meisei

Figura 6. Comparación de la base de los peines de especies de Centruroides: C. hirsutipalpus, C. tecomanus y C. meisei. Hembras (izq.); machos (der.). 
pigmento que ocupan el pretergito y sólo de manera muy difusa puede apreciarse pigmento en el postergito, mientras que en $C$. chamela las bandas se forman por manchas de pigmento tanto en el pretergito como en postergito e incluso se unen difusamente en la porción media de los tergitos (Figs. 2d, e); b), la base de los peines de los machos también ayuda a separar estas especies, ya que en C. elegans el borde posterior está claramente lobulado, a diferencia del borde casi recto de la nueva especie (Fig. 5); c), el tamaño que en C. elegans es claramente mayor (74.72 $\mathrm{mm}$ en los 2 machos medidos y $63.37 \mathrm{~mm}$ en las 4 hembras), así como en todas sus medidas (Cuadro 3); d), el número de dientes pectíneos en los machos de $C$. elegans llega a 24 o 25, contra los 17-20 (dominancia de 18-19) de la especie nueva y e), las carenas de las manos de los machos de C. elegans son claramente granulosas, "aperladas" según Pocock (1902), mientras que en la especie nueva, son casi lisas o sólo ligeramente granulosas.

Dimorfismo sexual. El tamaño de las hembras tiende a ser ligeramente mayor que el de los machos aunque en los ejemplares revisados ( 8 hembras y 9 machos) no se detectó diferencia estadística entre sexos (Cuadro 2). En esta especie, como en otros Centruroides, se pueden encontrar diferencias aparentes entre las hembras y los machos en la forma de la base de los peines, la cual en los machos presenta una escotadura media y es rectan- gular, y el margen posterior es casi recto; mientras que en las hembras el margen anterior es casi recto y sólo tiene una ligera escotadura, y el posterior es claramente redondeado (Fig. 5). Morfométricamente, esta diferencia se manifiesta en la proporción entre el ancho y la longitud de la base de los peines que en hembras tiene valores promedio de $1.86( \pm 0.14)$ y en los machos los valores están alrededor de $1.60( \pm 0.74)$. La diferencia en la proporción entre la longitud corporal y la del metasoma también es clara, con valores más bajos para los machos $(1.49 \pm$ $0.02)$ respecto al de las hembras $(1.66 \pm 0.04)$, lo que refleja la mayor longitud del metasoma de los machos en comparación con el total del cuerpo del animal. Estadísticamente, la vesícula de los machos es más larga (3.10 $\pm 0.12)$ que la de las hembras (2.94 \pm 0.07$)$, así como los segmentos caudales, que son más largos en los machos y más anchos en las hembras (véase Cuadro 2). Las carenas de la mano del pedipalpo en las hembras son más definidas y granulosas.

\section{Agradecimientos}

Al Instituto Bioclon, México, D. F., por el apoyo económico brindado. A la SEMARNAT, por el permiso de recolector científico (FAUT-0175) para el segundo autor, y a los revisores anónimos por los comentarios y correcciones en el manuscrito.

Cuadro 3. Medidas tomadas a 6 ejemplares adultos de Centruroides elegans provenientes de la misma zona en que habita $C$. chamela

\begin{tabular}{|c|c|c|c|c|c|c|}
\hline \multirow[b]{2}{*}{ Medidas tomadas } & \multicolumn{2}{|c|}{ Machos (Medidas en mm) } & \multicolumn{4}{|c|}{ Hembras (Medidas en mm) } \\
\hline & Ejemplar 1 & Ejemplar 2 & Ejemplar 1 & Ejemplar 2 & Ejemplar 3 & Ejemplar 4 \\
\hline $\begin{array}{l}\text { Carapacho (Largo/Ancho posterior/Ancho } \\
\text { anterior }\end{array}$ & $6.65 / 6.25 / 4.24$ & $6.15 / 5.94 / 4.09$ & $6.63 / 6.68 / 4.14$ & $6.65 / 6.73 / 4.24$ & $6.58 / 6.12 / 3.97$ & $6.78 / 6.65 / 4.19$ \\
\hline Long. del mesosoma incluyendo SMVII & 20.27 & 18.82 & 16.56 & 21.34 & 18.31 & 21.39 \\
\hline Conteo pectinal & $23-23$ & $24-24$ & $23-23$ & $23-23$ & $22-22$ & $22-21$ \\
\hline Segmento caudal I (Largo/Ancho) & $7.24 / 3.33$ & $6.76 / 3.12$ & $5.71 / 3.48$ & $5.82 / 3.78$ & $5.38 / 3.58$ & $5.82 / 3.76$ \\
\hline Segmento caudal II (Largo/Ancho) & $9.04 / 3.18$ & $8.13 / 2.95$ & $6.43 / 3.33$ & $6.58 / 3.53$ & $6.1 / 3.3 .33$ & $6.83 / 3.58$ \\
\hline Segmento caudal III (Largo/Ancho) & $9.8 / 3.1$ & $8.61 / 2.92$ & $6.73 / 3.23$ & $6.73 / 3.53$ & $6.63 / 3.2$ & $7.32 / 3.45$ \\
\hline Segmento caudal IV (Largo/Ancho) & $9.78 / 3.05$ & $8.79 / 2.78$ & $6.76 / 3.02$ & $7.19 / 3.53$ & $6.76 / 3.07$ & $7.29 / 3.35$ \\
\hline Segmento caudal V (Largo/Ancho) & $10.74 / 2.95$ & $9.45 / 2.77$ & $7.57 / 2.92$ & $7.16 / 3.25$ & $7.49 / 2.18$ & $8.41 / 3.12$ \\
\hline Vesícula (Largo/Ancho/Alto) & $4.85 / 2.44 / 2.46$ & $4.37 / 2.16 / 2.00$ & $3.40 / 2.06 / 2.13$ & $3.33 / 2.12 / 2.28$ & $3.68 / 2.18 / 2.16$ & $4.12 / 2.41 / 2.34$ \\
\hline Aguijón & 2.92 & 2.97 & 2.97 & 3.33 & 2.87 & 3.18 \\
\hline Long. metasoma incluyendo vesícula & 51.45 & 46.11 & 36.60 & 36.81 & 36.04 & 39.79 \\
\hline Fémur (Largo/Ancho) & $7.01 / 1.73$ & $6.22 / 1.68$ & $6.35 / 1.75$ & $6.32 / 1.9$ & $6.17 / 1.83$ & $6.4 / 1.91$ \\
\hline Patela (Largo/Ancho) & $7.52 / 2.29$ & $6.78 / 2.34$ & $6.55 / 2.41$ & $6.98 / 2.67$ & $6.6 / 2.51$ & $6.88 / 2.62$ \\
\hline Mano (Largo/Ancho/Alto) & $4.88 / 2.85 / 2.79$ & $4.24 / 2.84 / 2.49$ & $4.01 / 2.46 / 2.26$ & $4.14 / 2.41 / 2.36$ & $3.99 / 2.44 / 2.31$ & $4.19 / 2.59 / 2.54$ \\
\hline Dedo fijo & 6.60 & 5.74 & 6.14 & 6.53 & 6.73 & 6.83 \\
\hline Dedo móvil & 8.03 & 6.68 & 7.44 & 7.92 & 7.57 & 8.08 \\
\hline Base de los peines (Largo/Ancho) & $0.64 / 1.42$ & $0.64 / 1.39$ & $0.89 / 1.63$ & $0.75 / 1.8$ & $0.81 / 1.6$ & $0.91 / 1.7$ \\
\hline Proporción L/A de la base de los peines & 0.45 & 0.46 & 0.55 & 0.42 & 0.51 & 0.54 \\
\hline Proporción L corporal/L metasoma & 1.52 & 1.54 & 1.63 & 1.76 & 1.69 & 1.71 \\
\hline Longitud corporal & 78.37 & 71.08 & 63. & 64.80 & 60.93 & 67.96 \\
\hline Promedio: machos $=74.72 ;$ hembras $=63.37$ & & & & & & \\
\hline
\end{tabular}




\section{Literatura citada}

Armas, L. F. de, E. Martín-Frías y J. Estévez-Ramírez. 2003. Lista anotada de las especies mexicanas del género Centruroides Marx, 1890 (Scorpiones, Buthidae). Revista Ibérica de Aracnología 8:93-98.

Armas, L. F. de y E. Martín-Frías. 2008. El género Centruroides Marx, 1890 (Scorpiones: Buthidae) en el estado de Veracruz, México. Boletín de la Sociedad Entomológica Aragonesa 43:7-22.

Beutelspacher, B. C. R. 1999. Bromeliáceas como ecosistemas. Plaza y Valdez, México, D. F. 116 p.

Beutelspacher, B. C. R. 2000. Catálogo de los alacranes de México. Universidad Michoacana de San Nicolás de Hidalgo, Morelia, Michoacán. 175 p.

Díaz-Nájera, A. 1975. Listas y datos de distribución geográfica de los alacranes de México (Scorpionida). Revista de Investigaciones en Salud Pública (México) 35:1-36.

Fet, V., W. D. Sissom, G. Lowe y M. E. Braunwalder. 2000. Catalog of the scorpions of the world (1758-1998). The New York Entomological Society, New York. 690 p.

Francke, O. F. 1977. Scorpions of the genus Diplocentrus from Oaxaca, Mexico. Journal of Arachnology 4:145- 200.

García-Oliva, F, A. Camou y J. M. Maass. 2002. El clima de la región central de la costa del Pacifico Mexicano In Historia Natural de Chamela, F. A. Noguera, J. H. Vega-Rivera, A. N. García-Aldrete y M. Quezada-Avendaño (eds.). Instituto de Biología, UNAM, México, D. F p. 3-10.

González-Santillán, E. 2001. Catálogo de escorpiones de la Colección Nacional de Arácnidos (CNAN). Tesis, Facultad de Ciencias, Universidad Nacional Autónoma de México, México, D. F. 148 p.

González-Santillán, E. 2004. Diversidad, taxonomía y hábitat de alacranes. In Artrópodos de Chamela, A. N. García Aldrete y R. Ayala (eds.). Instituto de Biología, UNAM. México, D.F. p. 25-35.

González-Soriano, E., O. Delgado-Hernández y G. L. Harp. 2004. Libélulas de la Estación de Biología Chamela (Insecta:Odonata). In Artrópodos de Chamela, A. N. García Aldrete y R. Ayala (eds.). Instituto de Biología, UNAM, México, D. F. p. 37-61.

Hoffmann, C. C. 1931. Monografías para la entomología médica de México. Monografía No. 2, Los escorpiones de México (primera parte): Diplocentridae, Chactidae, Vejovidae. Anales del Instituto de Biología, Universidad Nacional Autónoma de México, Serie Zoología 2:291-408.

Hoffmann, C. C. 1932. Monografías para la entomología médica de México. Monografía No. 2, Los escorpiones de México (segunda parte): Buthidae. Anales del Instituto de Biología, Universidad Nacional Autónoma de México, Serie Zoología $3: 243-361$

Lourenço, W. R. y W. D. Sissom. 2000. Scorpiones. In Biodiversidad, taxonomía y biogeografía de artrópodos de México. Hacia una síntesis de su conocimiento, vol. 2, J. Llorente-Bousquets, E. González-Soriano y N. Papavero (eds.). Facultad de Ciencias, Universidad Nacional Autónoma de México/ CONABIO/ BAYER. México, D. F. p 115-135.

Pocock, R. I. 1902. Arachnida, Scorpiones, Pedipalpi and Solifugae. In Biologia Centrali-Americana. F. D. Godman and O. Salvin (eds.). Taylor and Francis, London. 71 p.

Ponce-Saavedra, J. y O. F. Francke. 2009. Descripción de una especie nueva de alacrán con importancia médica del género Centruroides (Scorpiones: Buthidae) del estado de Colima, México. Revista Mexicana de Biodiversidad 80:647- 658.

Ponce-Saavedra, J., O. F. Francke, H. Cano-Camacho y E. Hernández-Calderón. 2009. Evidencias morfológicas y moleculares que validan como especie a Centruroides tecomanus (Scorpiones, Buthidae). Revista Mexicana de Biodiversidad 80:71-84.

Ponce-Saavedra, J. y R. J. Moreno-Barajas. 2005. El género Centruroides Marx 1890 (Scorpiones: Buthidae) en México. Biológicas 7:42-51.

Quijano-Ravell, A. F., J. Ponce-Saavedra, O. F. Francke B. y M. A. Villaseñor-Ramos. 2010. Nuevos registros y distribución actualizada de Centruroides tecomanus Hoffmann, 1932 (Scorpiones: Buthidae). Ciencia Nicolaíta 52:179-189.

Rein, J. O. 2009. The Scorpion files. Norwegian University of Science and Technology, online at http://www.ub.ntnu.no/ scorpion-files/; última consulta: 10.I.2010.

Rzedowski, J. 1978. La vegetación de México. Limusa, México, D. F. 432 p.

Stahnke, H. L. 1970. Scorpion nomenclature and mensuration. Entomological News 81:297-316.

Vachon, M. 1974. Étude des caractères utilisés pour classer les familles et les genres de Scorpions (Arachnides). 1. La trichobothriotaxie en Arachnologie, sigles trichobothriaux et types de trichobothriotaxie chez les Scorpions. Bulletin du Muséum National d'Histoire Naturelle 3:857-958.

Vachon, M. 1975. Sur l'utilisation de la trichobothriotaxie du bras des pédipalpes des scorpions (Arachnides) dans le classement des genres de la famille des Buthidae Simon. Comptes Rendus Hebdomadaires des Séances de l'Académie des Sciences, série D 281:1597-1599.

Williams, S. C. 1986. A new species of Vaejovis from Jalisco, México (Scorpiones: Vaejovidae). The Pan-Pacific Entomologist 64:355-358. 